\title{
Formation of peroxide- and globin-derived radicals from the reaction of methaemoglobin and metmyoglobin with t-butyl hydroperoxide: an ESR spin-trapping investigation
}

\author{
Jolanda VAN DER ZEE \\ Department of Medical Biochemistry, Leiden University, Sylvius Laboratory, P.0. Box 9503, 2300 RA Leiden, The Netherlands
}

\begin{abstract}
The reaction of human methaemoglobin and horse metmyoglobin with t-butyl hydroperoxide (t-BuOOH) was investigated with the ESR spin-trapping technique. With the spin trap 5,5dimethyl-1-pyrroline $N$-oxide (DMPO) the formation of peroxyl, alkoxyl and methyl radicals derived from t-BuOOH could be detected. The relative contributions of these radicals were determined at various DMPO concentrations by computer simulation. From these data it could be concluded that the alkoxyl radical was the initial radical produced, which indicates that the hydroperoxide is cleaved homolytically. Further investigations, with the nitroso spin trap 2-methyl-2-nitrosopropane (MNP), showed the formation of globin-centred radicals. Non-specific proteolysis of the MNP adducts revealed isotropic three-line
\end{abstract}

spectra, which means that the radical adducts were centred on a tertiary carbon with no bonds to a hydrogen or nitrogen. Comparison with MNP adducts of several amino acids indicated that in methaemoglobin the radical adduct was most probably located on a valine residue. With metmyoglobin the same adduct was obtained, whereas an additional adduct could be assigned to a tyrosyl radical. These protein radicals most probably resulted from hydrogen abstraction by the metal-oxo species, formed by heterolytic cleavage of the hydroperoxide. These results therefore show that homolytic cleavage of the hydroperoxide leads to the formation of peroxide-derived radicals, whereas concurrent heterolytic cleavage results in protein-derived radicals.

\section{INTRODUCTION}

Considerable attention has been focused on the formation, stabilities and reactions of protein radicals in biological systems and the pathological consequences of such processes. Recent interest in protein radicals also stems from their proposed roles as intermediates in the catalytic mechanisms of several enzymes, in particular in the reaction of haem proteins with peroxides. The reaction between haem proteins and $\mathrm{H}_{2} \mathrm{O}_{2}$ is thought to proceed via two-electron oxidation, resulting in the formation of ferryl haem $\left(\mathrm{Fe}^{\mathrm{IV}}=\mathrm{O}\right)$, which is one oxidizing equivalent above the initial level, and a protein radical [1-6]. The mechanism by which the protein radical is generated, its location in the protein and the mechanisms by which it is dissipated are poorly understood. The nature of the metmyoglobin and methaemoglobin radical site was originally proposed to be a tyrosine radical [6-9] but this assignment has been contested [10,11]. In studies by Ortiz de Montellano and colleagues, a direct ESR signal was observed when a mutant protein, which lacked all tyrosine residues, was exposed to $\mathrm{H}_{2} \mathrm{O}_{2}$ [12,13]. This signal was identical with that found when the native protein was exposed to $\mathrm{H}_{2} \mathrm{O}_{2}$. However, observations such as the dityrosine cross-linking of sperm whale metmyoglobin by hydrogen peroxide and the covalent binding of tyrosine to haem indicate that oxidation of metmyoglobin by hydrogen peroxide forms one or more tyrosyl radicals $[14,15]$. Recently this was confirmed by Barr et al. [16], who showed that a tyrosyl radical could be trapped when horse metmyoglobin was exposed to hydrogen peroxide in the presence of the spin trap 2-methyl-2-nitrosopropane (MNP).

Less work has been done to determine what species are generated on the reaction of haem proteins with organic hydroperoxides. A complex ESR spectrum was observed in the reaction of sperm whale metmyoglobin and ethyl hydroperoxide, and was found to be a mixture of a tyrosyl radical and an unidentified free radical $[17,18]$. The latter radical was also observed with horse heart metmyoglobin, and it was suggested that the tyrosyl radical was formed on Tyr-151, which is present only in sperm whale metmyoglobin. A study on the reaction of methaemoglobin and a number of organic hydroperoxides also described the formation of tyrosyl radicals, but the signals were weak and poorly resolved [9]. The half-life of this radical was estimated as approx. $50 \mathrm{~s}$. It was suggested that the mechanism 'of their formation was similar to the mechanism with $\mathrm{H}_{2} \mathrm{O}_{2}$ '. However, recent ESR spin-trapping studies with cytochrome $c$ and haematin showed that the reaction of haem proteins and organic hydroperoxides most probably proceeds through a one-electron reduction of the hydroperoxide to form an alkoxyl radical as the first intermediate $[19,20]$. Thus there seems to be a difference between the reaction of haem proteins with $\mathrm{H}_{2} \mathrm{O}_{2}$ and the reaction with organic hydroperoxides. The reaction of haem proteins with organic peroxides was therefore studied further. Metmyoglobin and methaemoglobin were exposed to t-butyl hydroperoxide (t-BuOOH), and the formation of both peroxide- and proteinderived radicals was investigated with the spin traps 5,5-dimethyl1-pyrroline $N$-oxide (DMPO) and MNP.

\section{EXPERIMENTAL}

Pronase was obtained from Boehringer. Human methaemoglobin, horse metmyoglobin, t-BuOOH, MNP and DMPO were purchased from Sigma. To improve its purity, DMPO (1:1 dilution in water) was passed through a column containing 
activated charcoal [21]. The DMPO concentration was measured at $228 \mathrm{~nm}$, assuming a molar absorption coefficient of $7800 \mathrm{M}^{-1} \cdot \mathrm{cm}^{-1}$ [22]. All other reagents were of analytical grade and used without further purification. All solutions were prepared in water that had been passed through a Millipore Milli-Q ultrapurification system, and were made up freshly before use. MNP $(2 \mathrm{mg} / \mathrm{ml})$ was dissolved in $50 \mathrm{mM}$ sodium phosphate buffer, $\mathrm{pH} 7.4$, by stirring overnight in the dark. All experiments were performed at room temperature in $50 \mathrm{mM}$ sodium phosphate buffer, $\mathrm{pH}$ 7.4. Anaerobic conditions were obtained by bubbling with nitrogen.

ESR spectra were obtained with a JEOL RE2X spectrometer operating at $9.36 \mathrm{GHz}$ with a $100 \mathrm{kHz}$ modulation frequency, equipped with a TM110 cavity. The samples were transferred to the quartz flat cell by means of a rapid sampling device [23]. Hyperfine splittings were obtained with a program developed by David Duling (Laboratory of Molecular Biophysics, NIEHS, Research Triangle Park, NC, U.S.A.) [24]. The parameters used for simulating the experimental ESR spectra are described in the figure legends. The data for Figure 2 were obtained by simulating the low-field lines of each species. The component spectra were then double-integrated to give relative radical adduct concentrations. When ESR spectra were recorded at liquid nitrogen temperature, the spectrometer operating at $8.86 \mathrm{GHz}$ was equipped with a TM011 cavity and a fingertip liquid-nitrogen Dewar flask.

When samples were subjected to dialysis, several $\mathrm{ml}$ of sample were placed in dialysis tubing (pore size $2.4 \mathrm{~nm}$ ) and dialysed overnight at $4{ }^{\circ} \mathrm{C}$ against $50 \mathrm{mM}$ sodium phosphate buffer, $\mathrm{pH}$ 7.4. After dialysis a small aliquot was removed and spectra were scanned. The remaining sample was treated with pronase (final concentration $2 \mathrm{mg} / \mathrm{ml}$ ) for various periods at room temperature or $37^{\circ} \mathrm{C}$ and subsequently scanned. Control experiments were performed in parallel with complete incubations.

\section{RESULTS}

\section{Spin trapping of t-BuOOH-derived radicals with DMPO}

The results here are described for methaemoglobin, but comparable results were obtained with metmyoglobin. Incubation of methaemoglobin with t-BuOOH in the presence of DMPO gave a spectrum consisting of several DMPO radical adducts (Figure 1A). Deconvolution of the composite spectrum was performed by simulating each species separately by using the relative intensities and hyperfine values obtained from the composite computer simulation (Figures 1B to $1 \mathrm{~F}$ ). From their respective hyperfine coupling constants, the adducts could be assigned as alkoxyl $\left[a^{\mathrm{N}}=15.0 \mathrm{G}\right.$ and $a^{\mathrm{H}} \beta=16.5 \mathrm{G} ; 1$ gauss $=10^{-4}$ tesla $\left.(\mathrm{T})\right]$, peroxyl $\left(a^{\mathrm{N}}=14.4 \mathrm{G}, a^{\mathrm{H}} \beta=10.35 \mathrm{G}\right.$ and $\left.a^{\mathrm{H}} \gamma=1.4 \mathrm{G}\right)$, methyl $\left(a^{\mathrm{N}}=16.5 \mathrm{G}\right.$ and $\left.a^{\mathrm{H}} \beta=23.6 \mathrm{G}\right)$ and 5,5-dimethylpyrrolidone-2(oxy)-(1) (DMPOX) $\left[a^{\mathrm{N}}=7.3 \mathrm{G}\right.$ and $\left.a^{\mathrm{H}} \beta(2 \mathrm{H})=4.1 \mathrm{G}\right]$. These hyperfine splittings are in agreement with previous observations $[19,20,25]$. DMPOX is an oxidation product of DMPO that is thought to arise from the decomposition of DMPO/peroxyl radical adducts and/or from the reaction of haem iron with DMPO [26]. Control experiments showed that the signal was completely dependent on the presence of methaemoglobin and t-BuOOH (Figures $1 \mathrm{G}$ and $1 \mathrm{H}$ ). In addition, neither EDTA nor diethylenetriaminepenta-acetate had any effect on the concentration of radical adducts, which showed that the reactions were not mediated by free iron (results not shown).

The relative contributions of the peroxyl, alkoxyl and methyl radical adducts to the composite ESR spectrum were influenced by the concentration of DMPO. This is illustrated in Figure 2.

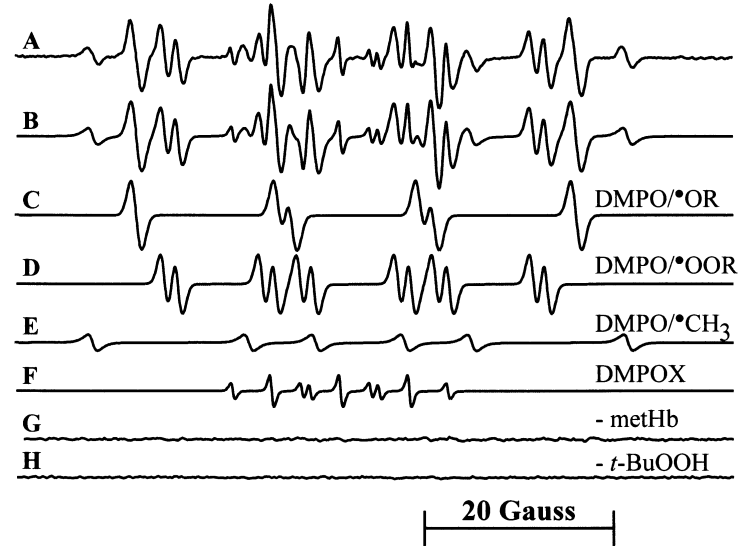

Figure 1 Computer simulation and deconvolution of the ESR spectrum obtained from a reaction mixture containing methaemoglobin and $\mathrm{t}-\mathrm{BuOOH}$

Samples contained $100 \mu \mathrm{M}$ methaemoglobin, $38 \mathrm{mM} \mathrm{t}-\mathrm{BuOOH}$ and $58 \mathrm{mM}$ DMPO. (A) Experimental spectrum; (B) composite computer simulation of $(\mathbf{A}) ;(\mathbf{C}-\mathbf{F})$ individual simulations of each species in the composite spectrum. Hyperfine coupling constants are given in the text. (C) Simulated spectrum for DMP0/OR: linewidth $0.58 \mathrm{G}$; line shape $100 \%$ Gaussian; mole ratio 0.34. (D) Simulated spectrum for DMP0/00R: linewidth $0.5 \mathrm{G}$; line shape $17 \%$ Lorentzian, $83 \%$ Gaussian; mole ratio 0.43. (E) Simulated spectrum for $\mathrm{DMPO} /{ }^{\circ} \mathrm{CH}_{3}$ : linewidth $0.77 \mathrm{G}$; line shape $80 \%$ Lorentzian, $20 \%$ Gaussian; mole ratio 0.17. (F) Simulated spectrum for DMPOX: linewidth $0.3 \mathrm{G}$; line shape $61 \%$ Lorentzian, 39\% Gaussian; mole ratio 0.05. (G) As (A) but without methaemoglobin. (H) As $(\mathbf{A})$ but without $\mathrm{t}-\mathrm{BuOOH}$. The spectrometer conditions were as follows: modulation amplitude, $0.5 \mathrm{G}$; microwave power, $20 \mathrm{~mW}$; time constant, $0.3 \mathrm{~s}$; scan time, $6 \mathrm{~min}$; scan range, $80 \mathrm{G}$. [Note: 1 gauss $=10^{-4}$ tesla (T).]

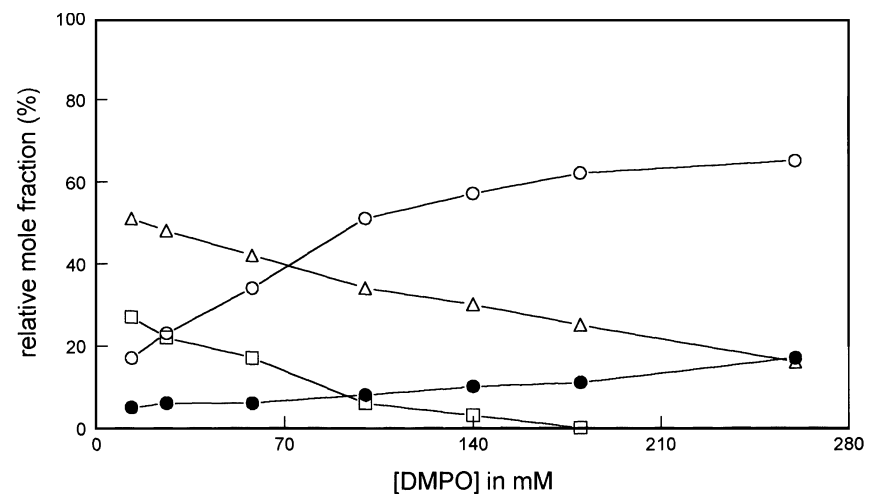

Figure 2 Effect of DMPO on the relative contributions of the radical adducts in a methaemoglobin/t-BuOOH system

Reaction mixtures contained $100 \mu \mathrm{M}$ methaemoglobin, $38 \mathrm{mM}$ t-BuOOH and various DMPO concentrations. Symbols: $\bigcirc, \mathrm{DMPO} /{ }^{\circ} \mathrm{OR} ; \triangle, \mathrm{DMPO} /{ }^{\circ} \mathrm{OOR} ; \square, \mathrm{DMPO} /{ }^{\circ} \mathrm{CH}_{3} ; \boldsymbol{O}, \mathrm{DMPOX}$.

The peroxyl radical adduct comprised approx. $51 \%$ of the composite spectrum at a DMPO concentration of $13 \mathrm{mM}$, whereas this decreased to $16 \%$ at a DMPO concentration of $260 \mathrm{mM}$. At the same time, the methyl radical adduct decreased from $27 \%$ to $0 \%$. The relative contribution of the alkoxyl radical adduct, in contrast, increased from approx. $17 \%$ to $65 \%$ of the composite spectrum. Thus as the DMPO concentration was increased, the relative contribution of the peroxyl and methyl radical adducts decreased, whereas the contribution of the alkoxyl radical adduct increased (Figure 2). 


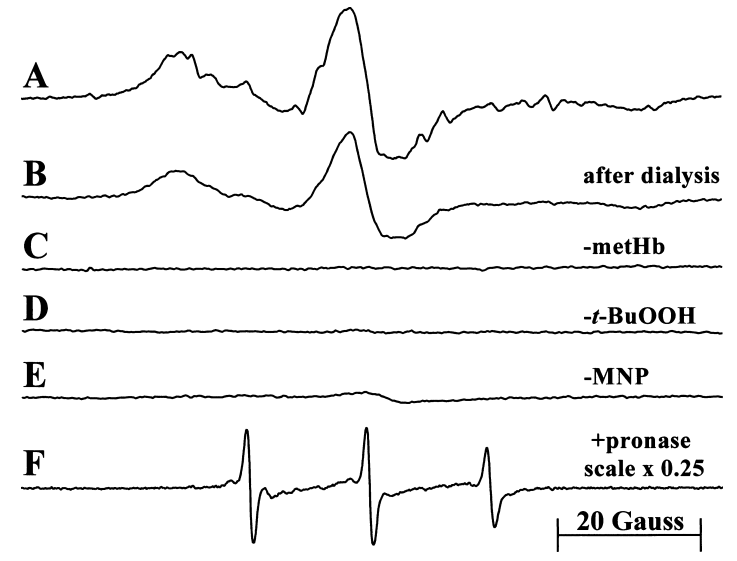

Figure 3 ESR spectra obtained after addition of t-BuOOH to methaemoglobin in the presence of MNP

(A) ESR spectrum after incubation of $100 \mu \mathrm{M}$ methaemoglobin with $5 \mathrm{mM} \mathrm{t}-\mathrm{BuOOH}$ in the presence of $23 \mathrm{mM}$ MNP for $10 \mathrm{~min}$. (B) ESR spectrum of an aliquot of the solution used to obtain spectrum (A) after dialysis overnight. (C) As (B) but without methaemoglobin. (D) As (B) but without t-BuOOH. (E) As (B) but without MNP. (F) An aliquot of the solution used to obtain spectrum (B) was treated with pronase $(2 \mathrm{mg} / \mathrm{ml})$ for $105 \mathrm{~min}$. Instrument settings for scans (A-E) were as follows: modulation amplitude, $2.5 \mathrm{G}$; microwave power, $20 \mathrm{~mW}$; time constant, $1 \mathrm{~s}$; scan time, $10 \mathrm{~min}$; scan range, $100 \mathrm{G}$. For scan $(\mathbf{F})$ settings were: modulation amplitude, $1 \mathrm{G}$; time constant, $0.3 \mathrm{~s}$.

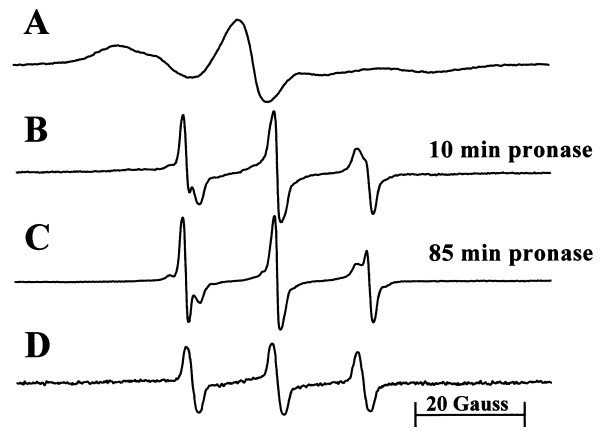

Figure 4 ESR spectra obtained after addition of t-BuOOH to metmyoglobin in the presence of MNP

(A) Metmyoglobin $(400 \mu \mathrm{M})$ was incubated with $5 \mathrm{mM} \mathrm{t}-\mathrm{BuOOH}$ in the presence of $23 \mathrm{mM}$ MNP for 10 min and dialysed overnight. (B) An aliquot of the solution used to obtain spectrum (A) was treated with pronase $(2 \mathrm{mg} / \mathrm{ml})$ for $10 \mathrm{~min}$. (C) An aliquot of the solution used to obtain spectrum (A) was treated with pronase $(2 \mathrm{mg} / \mathrm{ml})$ for $85 \mathrm{~min}$. (D) As (B) but metmyoglobin was incubated with $400 \mu \mathrm{M} \mathrm{H}_{2} \mathrm{O}_{2}$. Spectrometer settings for (A) were as in Figure $3(\mathrm{~A})$ and for (B-D) as in Figure 3(F).

\section{Spin trapping of globin-derived radicals with MNP}

Incubation of methaemoglobin with $\mathrm{t}-\mathrm{BuOOH}$ in the presence of MNP resulted in the detection of an ESR spectrum characteristic of a highly immobilized nitroxide with $a^{\mathrm{N}}=32.7 \mathrm{G}$ (Figure 3A). Superimposed on the signal were the signals formed as a result of the spin trapping of $\mathrm{t}-\mathrm{BuOOH}$-derived radicals by MNP. Maximal signal intensity was reached after $10 \mathrm{~min}$ of incubation. Only moderate decay of the immobilized signal occurred on dialysis (Figure 3B). The formation of the immobilized nitroxide was completely dependent on the presence of methaemoglobin, $\mathrm{t}$ $\mathrm{BuOOH}$ and MNP (Figures $3 \mathrm{C}$ to $3 \mathrm{E}$ ). Treatment of the product with pronase resulted in the detection of a three-line spectrum with hyperfine coupling constant $a^{\mathrm{N}}=16.8 \mathrm{G}$ (Figure 3F). No

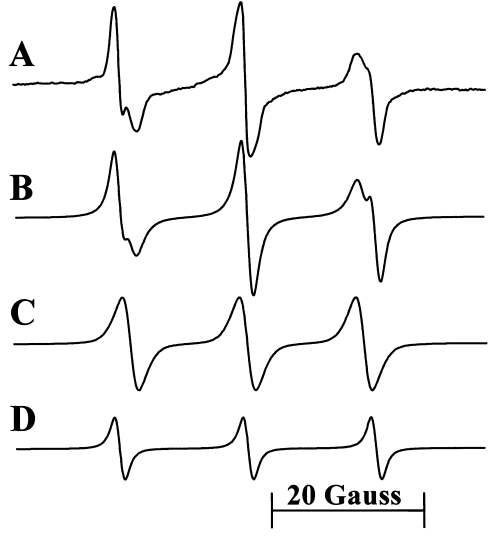

Figure 5 Computer simulation of the spectrum obtained after short pronase treatment of metmyoglobin exposed to $\mathrm{t}-\mathrm{BuOOH}$ in the presence of MNP

(A) Metmyoglobin $(400 \mu \mathrm{M})$ was incubated with $5 \mathrm{mM} \mathrm{t}-\mathrm{Bu} 00 \mathrm{H}$ in the presence of $23 \mathrm{mM}$ MNP for $10 \mathrm{~min}$, dialysed overnight and treated with pronase $(2 \mathrm{mg} / \mathrm{ml})$ for $10 \mathrm{~min}$. (B) Composite simulation of (A). (C) Simulated spectrum for the triplet with $a^{\mathrm{N}}=15.4 \mathrm{G}$ : linewidth $1.5 \mathrm{G}$; line shape $79 \%$ Lorentzian, $21 \%$ Gaussian; mole ratio 0.4. (D) Simulated spectrum for the triplet with $a^{N}=16.8 \mathrm{G}$ : linewidth $0.9 \mathrm{G}$; line shape $100 \%$ Lorentzian; mole ratio 0.6 .

signal could be detected in control samples, without either t$\mathrm{BuOOH}$ or MNP, that were treated with pronase after dialysis (results not shown).

In contrast with $\mathrm{H}_{2} \mathrm{O}_{2}$, with $\mathrm{t}-\mathrm{BuOOH}$ peroxide-derived radicals are formed, which could oxidize amino acids in methaemoglobin and in this way give an MNP-radical adduct. Therefore the experiment with MNP (Figures 3A, 3B and 3F) was also performed in the presence of $200 \mathrm{mM}$ DMPO, which traps t-BuOOH-derived radicals and thus prevents a reaction with the protein. In the presence of DMPO exactly the same results were obtained as without DMPO. It was also investigated whether iron, which can be released from the haem group on degradation, was involved in the formation of the globin-derived radicals. However, the same results were obtained when $100 \mu \mathrm{M}$ diethylenetriaminepenta-acetate was added to the incubation mixtures (results not shown).

When metmyoglobin was incubated with t-BuOOH in the presence of MNP, a highly immobilized nitroxide with $a_{1}=$ $28.8 \mathrm{G}$ was obtained, which was stable enough to be dialysed (Figure 4A). After treatment with pronase for $10 \mathrm{~min}$ the spectrum shown in Figure 4(B) was obtained, which was changed by further treatment with pronase into the spectrum shown in Figure 4(C). Simulation was difficult as the high-field lines were broadened as result of the slower molecular motion, which is consistent with the high molecular mass of the radical adduct from pronase-treated metmyoglobin. The simulation for the spectrum obtained after treatment with pronase for $10 \mathrm{~min}$ is shown in Figure 5(B), with the separate triplets in Figures 5(C) and 5(D). The spectrum consisted of two triplets: one with splitting constant $a^{\mathrm{N}}=16.8 \mathrm{G}$, and another with $a^{\mathrm{N}}=15.4 \mathrm{G}$. The latter was dominant after short incubation with pronase, whereas the former appeared more clearly after longer treatment with pronase (Figures 4B and 4C). For comparison the spectrum obtained by pronase treatment of metmyoglobin, exposed to hydrogen peroxide in the presence of MNP, is shown, which consists of one triplet with $a^{\mathrm{N}}=15.4 \mathrm{G}$ (Figure 4D). This result is in accordance with previous observations [16,27]. 


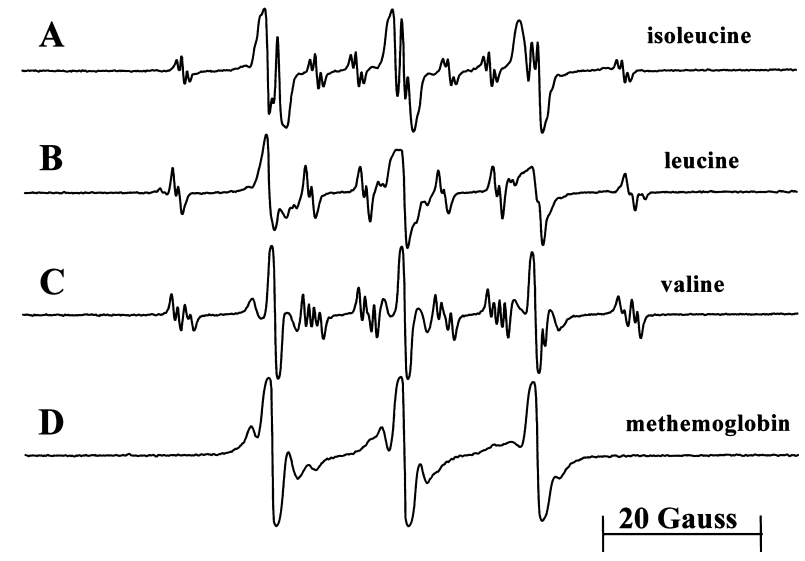

Figure 6 ESR spectra obtained after exposure of amino acids to hydroxyl radicals in the presence of MNP: comparison with methaemoglobin treated with $\mathrm{t}-\mathrm{BuOOH}$

(A) Isoleucine $(20 \mathrm{mM})$ was incubated with $2 \mathrm{mM} \mathrm{Fe}^{2+}$ and $2.5 \mathrm{mM} \mathrm{H}_{2} \mathrm{O}_{2}$ in the presence of $23 \mathrm{mM}$ MNP. (B) As (A) but with $20 \mathrm{mM}$ leucine. (C) As (A) but with $20 \mathrm{mM}$ valine. (D) Methaemoglobin $(500 \mu \mathrm{M})$ was incubated with $10 \mathrm{mM} \mathrm{t}-\mathrm{BuOOH}$ in the presence of $23 \mathrm{mM}$ MNP, dialysed overnight, diluted $1: 1$ and subsequently treated with pronase $(2 \mathrm{mg} / \mathrm{ml})$ for 75 min at $37^{\circ} \mathrm{C}$. Spectrometer settings for scans (A-C) were: modulation amplitude, $0.5 \mathrm{G}$; microwave power, $20 \mathrm{~mW}$; time constant, $0.1 \mathrm{~s}$; scan time, $10 \mathrm{~min}$; scan range, $100 \mathrm{G}$. For scan (D) thesettings were: modulation amplitude, $1 \mathrm{G}$; time constant, $0.3 \mathrm{~s}$.

\section{Oxidation of amino acids}

Structural information about trapped radicals can be obtained by using a nitroso spin trap such as MNP. Nitroso compounds have a distinct advantage over nitrones such as DMPO because the reactive free radical attaches directly to the nitroxide nitrogen atom, which will give rise to additional hyperfine splitting constants. The lack of additional hyperfine structure in the spectra obtained after pronase treatment of the haem proteins therefore indicates that the tertiary carbon atom in the adduct has no bonds to atoms with nuclear spin such as nitrogen or hydrogen. In the case of a one-electron oxidation reaction the most likely positions are $\mathrm{C}-3$ of the indole ring of tryptophan and C-4 of the phenol ring of tyrosine. When tryptophan was incubated with methaemoglobin and $\mathrm{t}-\mathrm{BuOOH}$ in the presence of MNP, a three-line spectrum was detected with hyperfine splitting constant $a^{\mathrm{N}}=15.8 \mathrm{G}$ (result not shown). With tyrosine, however, no radical was detected. However, when tyrosine was incubated with horseradish peroxidase and $\mathrm{H}_{2} \mathrm{O}_{2}$ in the presence of MNP a triplet was detected with $a^{\mathrm{N}}=15.4 \mathrm{G}$ (results not shown), as was also observed by Barr et al. [16].

A radical on a tertiary carbon atom can also be formed through abstraction of a hydrogen. Possible candidates are the amino acids valine, isoleucine, leucine, threonine and proline. Data in the literature showed that MNP adducts of tertiary carbon-centred radicals with a hyperfine splitting between 16.3 and $16.7 \mathrm{G}$ can be obtained on exposure of valine, leucine and isoleucine to hydroxyl radicals, generated by photolysis of $\mathrm{H}_{2} \mathrm{O}_{2}$ [28]. Incubation of these amino acids with methaemoglobin and $\mathrm{t}-\mathrm{BuOOH}$ in the presence of MNP did not give the formation of radical adducts.

In subsequent experiments isoleucine, leucine and valine were exposed to hydroxyl radicals, generated by $\mathrm{Fe}^{2+}$ and $\mathrm{H}_{2} \mathrm{O}_{2}$, in the presence of MNP. The spectra shown in Figures 6(A) to 6(C) were compared with a spectrum that was obtained at a higher methaemoglobin concentration, which showed signals in addition to the main triplet of $16.8 \mathrm{G}$ (Figure 6D). The hyperfine splitting
Table 1 Hyperfine coupling constants of radical adducts generated from the reaction of amino acids with hydroxyl radicals in the presence of MNP: comparison with methemoglobin treated with $\mathrm{t}-\mathrm{BuOOH}$

Reaction conditions were as described in the legend to Figure 6. Hyperfine coupling constants are given in gauss. [Note: 1 gauss $=10^{-4}$ tesla (T).]

\begin{tabular}{|c|c|c|c|c|c|c|}
\hline Source & Trapped species & $a^{N}$ & $a^{\mathrm{N}} \beta$ & $a^{\mathrm{H}} \beta 1$ & $a^{\mathrm{H}} \beta 2$ & Percentage of total \\
\hline $\begin{array}{l}\text { Valine* } \\
\text { MNP }\end{array}$ & $\begin{array}{l}\cdot \mathrm{CH}_{2-}^{-} \\
\cdot \mathrm{CH}_{2}^{-} \\
>{ }^{-} \mathrm{C}- \\
\cdot \cdot \mathrm{CN}-\end{array}$ & $\begin{array}{l}16.75 \\
16.5 \\
16.5 \\
16.75 \\
17.2\end{array}$ & 2.15 & $\begin{array}{l}24.9 \\
22.0\end{array}$ & $\begin{array}{l}0.65 \\
0.70\end{array}$ & $\begin{array}{r}12 \\
12 \\
29 \\
40 \\
6\end{array}$ \\
\hline Leucine $†$ & $\begin{array}{l}\cdot \mathrm{CH}_{2-}^{-} \\
\cdot \mathrm{CH}_{2-}^{-} \\
>{ }^{\circ} \mathrm{C}- \\
\cdot{ }^{\circ} \mathrm{CH}-\end{array}$ & $\begin{array}{l}16.8 \\
16.6 \\
16.85 \\
16.45 \\
17.2\end{array}$ & & $\begin{array}{l}23.75 \\
27.4 \\
1.9\end{array}$ & $\begin{array}{l}0.65 \\
0.60\end{array}$ & $\begin{array}{r}13 \\
5 \\
60 \\
19 \\
3\end{array}$ \\
\hline $\begin{array}{l}\text { Isoleucine } \neq \\
\text { MNP }\end{array}$ & $\begin{array}{l}\cdot \mathrm{CH}_{2}- \\
\cdot \mathrm{CH}_{2}^{-} \\
-\mathrm{CH}- \\
\cdot \mathrm{C}<\end{array}$ & $\begin{array}{l}16.95 \\
16.9 \\
16.5 \\
16.6 \\
17.2\end{array}$ & & $\begin{array}{r}22.75 \\
21.45 \\
1.85\end{array}$ & $\begin{array}{l}0.60 \\
0.60\end{array}$ & $\begin{array}{r}5 \\
6 \\
74 \\
9 \\
6\end{array}$ \\
\hline Methaemoglobin & $\begin{array}{l}>\cdot \mathrm{C}- \\
-\mathrm{CN}-\end{array}$ & $\begin{array}{l}16.8 \\
16.55\end{array}$ & 2.4 & & & $\begin{array}{l}37 \\
63\end{array}$ \\
\hline $\begin{array}{l}\text { * Structure of } \\
+ \text { Structure } \\
+ \text { Structure }\end{array}$ & $\begin{array}{l}\text { aline: }\left(\mathrm{CH}_{3}\right)_{2} \mathrm{CHCH} \\
\text { eucine: }\left(\mathrm{CH}_{3}\right)_{2} \mathrm{CHC} \\
\text { soleucine: } \mathrm{CH}_{3} \mathrm{CH}_{2}\end{array}$ & $\begin{array}{l}\left.\mathrm{NH}_{3}{ }^{+}\right) \mathrm{CO} \\
\mathrm{H}_{2} \mathrm{CH}(\mathrm{NH} \\
\mathrm{CH}\left(\mathrm{CH}_{3}\right) \mathrm{C}\end{array}$ & $\begin{array}{l}\mathrm{O}_{2}^{-} \text {. } \\
\left.\mathrm{H}_{3}^{+}\right) \mathrm{CC} \\
\mathrm{CH}(\mathrm{NH}\end{array}$ & $\mathrm{O}_{2}^{-}$ & & \\
\hline
\end{tabular}

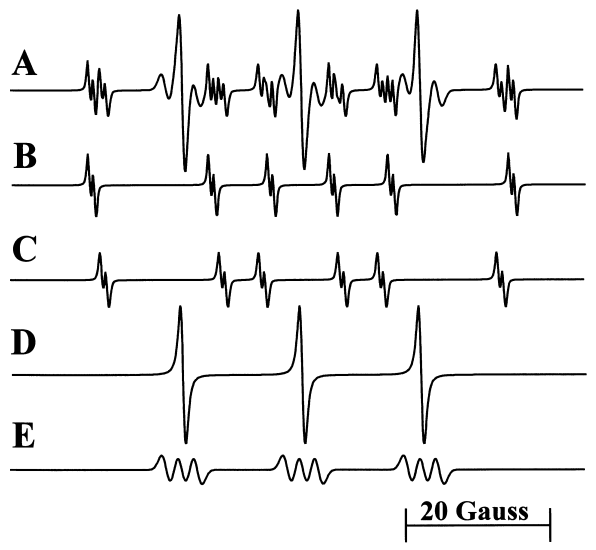

Figure 7 Computer simulation of the ESR spectrum obtained after exposure of valine to hydroxyl radicals

(A) Composite computer simulation of Figure 5(C). The hyperfine coupling constants of each species are listed in Table 1. (B) Simulated spectrum of $\mathrm{MNP} /{ }^{\circ} \mathrm{CH}_{2} \mathrm{CH}\left(\mathrm{CH}_{3}\right) \mathrm{CH}\left(\mathrm{NH}_{3}{ }^{+}\right) \mathrm{CO}_{2}{ }^{-}$: line width $0.2 \mathrm{G}$; line shape $81 \%$ Lorentzian, $19 \%$ Gaussian. (C) Simulated spectrum of $\mathrm{MNP} / \mathrm{CH}_{2} \mathrm{CH}\left(\mathrm{CH}_{3}\right) \mathrm{CH}\left(\mathrm{NH}_{3}{ }^{+}\right) \mathrm{CO}_{2}^{-}$: line width $0.25 \mathrm{G}$; line shape $65 \%$ Lorentzian, $35 \%$ Gaussian. (D) Simulated spectrum of $\mathrm{MNP} /\left(\mathrm{CH}_{3}\right)_{2}{ }^{\circ} \mathrm{CHC}\left(\mathrm{NH}_{3}{ }^{+}\right) \mathrm{CO}_{2}{ }^{-}$: line width $0.5 \mathrm{G}$; line shape $96 \%$ Lorentzian, $4 \%$ Gaussian. (E) Simulated spectrum of $\mathrm{MNP} /\left(\mathrm{CH}_{3}\right)_{2} \mathrm{CH} \cdot \mathrm{C}^{\circ}\left(\mathrm{NH}_{3}{ }^{+}\right) \mathrm{CO}_{2}{ }^{-}$: line width $0.64 \mathrm{G}$; line shape $100 \%$ Gaussian.

constants are listed in Table 1 and as illustration the simulation of the spectrum obtained with valine is given in Figure 7. All the spectra consisted of five species: four derived from the amino acid and a small contaminant signal from MNP, namely the dit-butyl nitroxide radical $\left(a^{\mathrm{N}}=17.2 \mathrm{G}\right)$. Two radical adducts came from hydrogen abstraction from the methyl groups of each amino acid (Figures $7 \mathrm{~B}$ and $7 \mathrm{C}$ ). The non-equivalence in the 


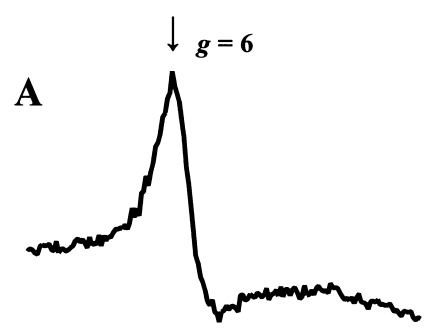

B

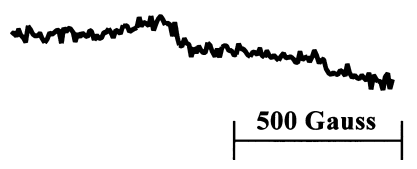

Figure 8 ESR spectrum of methaemoglobin at $77 \mathrm{~K}$ before and after addition of $\mathrm{t}-\mathrm{BuOOH}$

(A) Solution of $500 \mu \mathrm{M}$ methaemoglobin frozen in liquid nitrogen. (B) Methaemoglobin $(500 \mu \mathrm{M})$ was incubated with $10 \mathrm{mM} \mathrm{t}-\mathrm{BuOOH}$ for $20 \mathrm{~min}$ and the sample was frozen in liquid nitrogen. Spectrometer settings were: modulation amplitude, $10 \mathrm{G}$; microwave power, $1 \mathrm{~mW}$; time constant, $0.1 \mathrm{~s}$; scan rate $625 \mathrm{G} / \mathrm{min}$.

hyperfine splitting constants of the $\beta$-protons can be explained by the presence of two asymmetrical conformers produced by internal steric hindrance ([28], and references therein). The third species that was observed came from a tertiary carbon (Figure 7D). For leucine and isoleucine the final species came from a doublet, generated by hydrogen abstraction from a $\mathrm{CH}_{2}$ group. For valine, in contrast, the last species was simulated by using a hyperfine splitting $a^{\mathrm{N}}=16.5 \mathrm{G}$ and an additional coupling $a^{\mathrm{N}}=$ $2.1 \mathrm{G}$, coming from the nitrogen of the amino group (Figure 7E). This species can also be interpreted as a doublet $\left(a^{\mathrm{N}}=16.7 \mathrm{G}\right.$ and $a^{\mathrm{H}} \beta=4.3 \mathrm{G}$ ), assuming that a centre line from a nitrogen triplet is not hidden under the strong triplet spectrum. However, the splitting for the $\beta$-proton is too high in comparison with the splittings obtained for leucine and isoleucine (Table 1).

The similarity between the methaemoglobin spectrum and the spectrum of valine was apparent (Figures 6C and 6D). With methaemoglobin, the hyperfine splittings of the second species could be simulated by using $a^{\mathrm{N}}=16.5 \mathrm{G}$ (linewidth $0.9 \mathrm{G}$ ) and $a^{\mathrm{N}} \beta=2.4 \mathrm{G}$ (linewidth $1.2 \mathrm{G}$ ). There were still some additional lines present in the methaemoglobin signal, but these could not be identified further.

\section{ESR spectra at $77 \mathrm{~K}$}

Figure 8 shows the ESR spectrum of methaemoglobin in phosphate buffer frozen to $77 \mathrm{~K}$. The major signal at $g=6$ is typical of high-spin iron(III) in a haem environment [29]. Incubation of methaemoglobin with $\mathrm{t}-\mathrm{BuOOH}$ resulted in a decrease in this signal (Figure 8).

\section{DISCUSSION}

Two mechanisms exist for the reduction of organic hydroperoxides by haem proteins. In heterolytic cleavage the hydroperoxide undergoes two-electron reduction to its corresponding alcohol and haem iron is oxidized to a compound I-type species:

$\mathrm{t}-\mathrm{BuOOH}+$ porphyrin-Fe ${ }^{\mathrm{III}} \rightarrow \mathrm{t}-\mathrm{BuOH}+$ porphyrin $^{\cdot+}-\mathrm{Fe}^{\mathrm{IV}}=\mathrm{O}$

This species could then abstract hydrogen, producing a peroxyl radical and the ferryl form of the haem protein as shown in reaction (2). Self-reaction of tertiary peroxyl radicals will result in the formation of alkoxyl radicals, as in reaction (3) $[30,31]$ :

$$
\begin{array}{r}
\text { porphyrin }^{+}-\mathrm{Fe}^{\mathrm{IV}}=\mathrm{O}+\mathrm{t}-\mathrm{BuOOH} \rightarrow \text { porphyrin }^{+}-\mathrm{Fe}^{\mathrm{IV}}=\mathrm{O} \\
+\mathrm{t}-\mathrm{BuOO}^{\bullet}+\mathrm{H}^{+} \\
2 \mathrm{t}-\mathrm{BuOO}^{\cdot} \rightarrow 2 \mathrm{t}-\mathrm{BuO}^{\bullet}+\mathrm{O}_{2}
\end{array}
$$

Homolytic cleavage of the hydroperoxide, in contrast, will yield the alkoxyl radical as the initial radical:

$$
\begin{aligned}
\mathrm{t}-\mathrm{BuOOH}+\text { porphyrin-Fe } & \mathrm{III} \rightarrow \mathrm{t}-\mathrm{BuO}+\text { porphyrin-Fe }{ }^{\mathrm{IV}}=\mathrm{O} \\
& +\mathrm{H}^{+}
\end{aligned}
$$

Subsequent reaction of methyl radicals, formed through $\beta$ scission of the alkoxyl radical [reaction (5)], with oxygen will give methylperoxyl radicals, as in reaction (6):

$\mathrm{t}-\mathrm{BuO} \cdot \rightarrow{ }^{\cdot} \mathrm{CH}_{3}+$ acetone

$\cdot \mathrm{CH}_{3}+\mathrm{O}_{2} \rightarrow \cdot \mathrm{OOCH}_{3}$

Evidence has been obtained that heterolytic and homolytic cleavage can occur at the same time [32]. With the help of 4hydroperoxy-4-methyl-2,6-di-t-butylcyclohexa-2,5-dien-1-one, a peroxide that is converted heterolytically to an alcohol and homolytically to a number of rearranged products, it was determined that the homolytic/heterolytic product ratio for several haem proteins was 0.5 . This means that peroxide-derived radicals can be formed concurrently via reactions (2) and (4).

To determine what mechanism was responsible for the formation of peroxyl and alkoxyl radicals in the reaction of methaemoglobin or metmyoglobin with $\mathrm{t}-\mathrm{BuOOH}$, the following strategy was used: the reactions of the initial radical that occur after its formation can be suppressed by increasing the concentration of the spin trap, in this case DMPO. Thus as more spin trap is added, more of the initial radical is trapped, which prevents the initial radical from undergoing reactions that lead to secondary radicals. At low DMPO concentrations alkoxyl, peroxyl and methyl radical adducts were detected. At higher DMPO concentrations, however, the alkoxyl radical dominated, whereas the peroxyl and the methyl radical adducts decreased (Figure 2). These results strongly suggest that the alkoxyl radical is the initial radical, which means that the hydroperoxide is cleaved homolytically [reaction (4)]. This is in accordance with the results obtained with haematin and cytochrome $c[19,20]$. These results also indicate that peroxyl radicals are not formed via reaction (2). If such a reaction took place the peroxyl radical concentration would not have decreased, but should have increased as the DMPO concentration was increased (Figure 2). These results are in agreement with those of Allentoff et al. [32], who found that although substantial heterolytic cleavage of 4hydroperoxy-4-methyl-2,6-di-t-butylcyclohexa-2,5-dien-1-one took place [reaction (1)], only a very small quantity of peroxyl radicals was formed via reaction (2). Taken together, these results indicate that peroxyl radical formation results from $\beta$ scission of the alkoxyl radical and subsequent reaction of the methyl radical with oxygen [reactions (5) and (6)].

It has been suggested that reaction (4) might occur without a valence change of the haem iron and that an iron-bound hydroxyl radical might be formed [33]. However, the ESR spectra of methaemoglobin at $77 \mathrm{~K}$ showed that the signal in the $g=6$ region, assigned to the ferric prosthetic group, decreased considerably on exposure to t-BuOOH (Figure 8). This clearly showed that iron is no longer in its initial high-spin ferric state after reaction with $\mathrm{t}-\mathrm{BuOOH}$. 


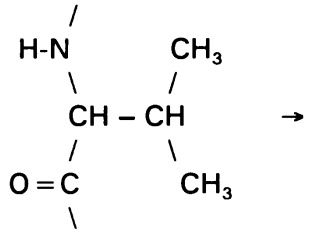

(valine)

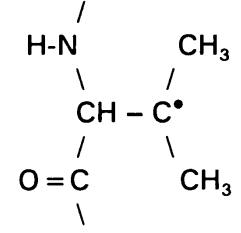

(A)

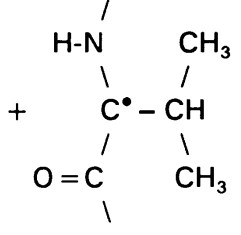

(B)

\section{Scheme 1 Proposed structure of valine radicals trapped by MNP}

Further investigations showed that incubation of methaemoglobin and metmyoglobin with $\mathrm{t}-\mathrm{BuOOH}$ also resulted in the formation of protein radicals (Figures 3 and 4). The high degree of rotational anisotropy in these immobilized signals can be removed by treatment with proteases, which results in fragmentation of the protein to relatively freely rotating peptides that give isotropic spectra [34]. With methaemoglobin a triplet with $a^{\mathrm{N}}=16.8 \mathrm{G}$ could be detected (Figure $3 \mathrm{~F}$ ). At higher methaemoglobin concentrations a second adduct with $a^{\mathrm{N}}=16.5 \mathrm{G}$ and a secondary nitrogen splitting of $2.4 \mathrm{G}$ could be identified (Figure 6D). Comparison of these results with the spectra of a number of amino acids that gave tertiary carbon-centred radicals on hydrogen abstraction showed that the globin-centred radical is most probably located on a valine residue (Table 1). The spectra obtained with valine and methaemoglobin showed a strong resemblance to each other and the results indicate that two different adducts from valine were trapped (Figures 6C and 6D). The structures of these radicals are outlined in Scheme 1.

Spin trapping of species (A) by MNP will give a triplet signal, which can be assigned to the adduct with $a^{\mathrm{N}}=16.8 \mathrm{G}$ (Figure 7D). A MNP adduct of a valine radical with $a^{\mathrm{N}}=16.8 \mathrm{G}$ has also been detected in a study by Davies et al. [35], where $\gamma$ irradiated proteins and amino acids were exposed to iron in the presence of MNP. Trapping of species (B) with MNP will result in a triplet, with each line split into three by the nitrogen (Figure 7E). Exposure of metmyoglobin to $\mathrm{t}-\mathrm{BuOOH}$ in the presence of MNP resulted in the detection of two triplets (Figure 5). One adduct had a hyperfine splitting constant of $16.8 \mathrm{G}$, as was found with methaemoglobin, which indicates that also in this case a radical located on a valine residue was trapped by MNP. The second triplet had a hyperfine splitting constant of $15.4 \mathrm{G}$, which was very similar to the triplet that could be detected after exposure of metmyoglobin to $\mathrm{H}_{2} \mathrm{O}_{2}$ (Figure 4). This adduct has recently been assigned to a tyrosyl radical; these results therefore strongly suggest that also with $\mathrm{t}-\mathrm{BuOOH}$ a tyrosyl radical is formed in metmyoglobin [16,27].

What mechanism could be responsible for the formation of these protein radicals? Two modes of $\mathrm{C}-\mathrm{H}$ activation can be observed when alkyl hydroperoxides are used as oxidants [36,37]. The first mechanism involves hydrogen abstraction by an alkoxyl radical, resulting from the homolytic cleavage [reaction (4)] of the hydroperoxide:

$\mathrm{t}-\mathrm{BuO}{ }^{\bullet}+\mathrm{R}_{3} \mathrm{C}-\mathrm{H} \rightarrow \mathrm{t}-\mathrm{BuOH}+\mathrm{R}_{3} \mathrm{C}^{\cdot}$

To investigate the involvement of alkoxyl radicals, the amino acids valine, isoleucine and leucine were exposed to alkoxyl radicals generated by methaemoglobin and $\mathrm{BuOOH}$. This did not result in the formation of MNP adducts of these amino acids, which suggests that alkoxyl radicals were unable to abstract a hydrogen atom from these amino acids. Secondly, the hydrogen can also be abstracted by a metal-oxo species, resulting from heterolytic cleavage [reaction (1)] of the $\mathrm{O}-\mathrm{O}$ bond of the peroxide:

$\operatorname{porphyrin}^{\cdot+}\left(\mathrm{Fe}^{\mathrm{IV}}=\mathrm{O}\right)+\mathrm{R}_{3} \mathrm{C}-\mathrm{H} \rightarrow \operatorname{porphyrin}\left(\mathrm{Fe}^{\mathrm{IV}}-\mathrm{OH}^{\cdot}\right)+\mathrm{R}_{3} \mathrm{C}^{\cdot}$

This would mean that heterolytic cleavage of the hydroperoxide by methaemoglobin and metmyoglobin results in the formation of protein-derived radicals, while concurrent homolytic cleavage of the peroxide results in peroxide-derived radicals. This concurrent heterolytic and homolytic cleavage would be in accordance with the product analysis study of Allentoff et al. [32]. Their data indicated that of the hydroperoxide that was degraded, $33 \%$ was cleaved homolytically and $67 \%$ was cleaved heterolytically.

The formation of protein-derived radicals by reaction (8) would be similar to the reaction of haem proteins with $\mathrm{H}_{2} \mathrm{O}_{2}$ [1-6]. It is therefore of interest that both with $\mathrm{H}_{2} \mathrm{O}_{2}$ and $\mathrm{t}-$ $\mathrm{BuOOH}$ a tyrosyl radical could be detected in metmyoglobin. Horse metmyoglobin contains two tyrosine residues, located at positions 103 and 146 [38]. It has been found that exposure of horse metmyoglobin to $\mathrm{H}_{2} \mathrm{O}_{2}$ resulted in covalent binding of Tyr103 (G4) to the prosthetic haem group [14]. This suggests that the tyrosyl radical might be located on Tyr-103. This would be in agreement with the fact that exposure of methaemoglobin to t$\mathrm{BuOOH}$ did not result in the detection of a tyrosyl radical: in human methaemoglobin the residue at position G4 is asparagine [38]. In both proteins a valine radical could be detected after exposure to $\mathrm{t}-\mathrm{BuOOH}$. A valine residue at position $\mathrm{E} 11$, which is packed against the haem ring, is present in haemoglobin [Val-62 ( $\alpha$-chain) or Val-67 ( $\beta$-chain)] and in myoglobin (Val-68) [38]. This proximity might facilitate a reaction between reactive species generated during the reaction and a valine residue. However, further investigations are required to determine the exact location of these radicals.

We thank Dr. Ron Mason and co-workers (Laboratory of Molecular Biophysics NIEHS, Research Triangle Park, NC, U.S.A.) for helpful discussions, and Mr. G. A. van Albada (Department of Bioinorganic Chemistry, Leiden University, Leiden, The Netherlands) for his help with the low-temperature ESR experiments.

\section{REFERENCES}

1 George, P. and Irvine, D. H. (1952) Biochem. J. 52, 511-517

2 George, P. and Irvine, D. H. (1955) Biochem. J. 60, 596-604

3 Gibson, J. F. and Ingram, D. J. E. (1956) Nature (London) 178, 871-872

4 Gibson, J. F., Ingram, D. J. E. and Nicholls, P. (1958) Nature (London) 181, 1398-1399

5 King, N. K. and Winfield, M. E. (1963) J. Biol. Chem. 238, 1520-1528

6 King, N. K., Looney, F. D. and Winfield, M. E. (1967) Biochim. Biophys. Acta 133, 65-82

7 Davies, M. J. (1991) Biochim. Biophys. Acta 1077, 86-90

8 Davies, M. J. and Puppo, A. (1992) Biochem. J. 281, 197-201

9 McArthur, K. M. and Davies, M. J. (1993) Biochim. Biophys. Acta 1202, 173-181

10 Kelman, D. J., DeGray, J. A. and Mason, R. P. (1994) J. Biol. Chem. 269, 7458-7463

11 Kelman, D. J. and Mason, R. P. (1992) Free Radical Res. Commun. 16, 27-33

12 Wilks, A. and Ortiz de Montellano, P. R. (1992) J. Biol. Chem. 267, 8827-8833

13 Rao, S. I., Wilks, A. and Ortiz de Montellano, P. R. (1993) J. Biol. Chem. 268, 803-809

14 Tew, D. and Ortiz de Montellano, P. R. (1988) J. Biol. Chem. 263, 17880-17886

15 Catalano, C. E., Choe, Y. S. and Ortiz de Montellano, P. R. (1989) J. Biol. Chem. 264, 10534-10541

16 Barr, D. P., Gunther, M. R., Deterding, L. J., Tomer, K. B. and Mason, R. P. (1996) J. Biol. Chem. 271, 15498-15503

17 Harada, K. and Yamazaki, I. (1987) J. Biochem. (Tokyo) 101, 283-286

18 Miki, H., Harada, K., Yamazaki, I., Tamura, M. and Watanabe, H. (1989) Arch. Biochem. Biophys. 275, 354-362

19 Barr, D. P. and Mason, R. P. (1995) J. Biol. Chem. 270, 12709-12716

20 Van der Zee, J., Barr, D. P. and Mason, R. P. (1996) Free Radicals Biol. Med. 20, 199-206 
21 Buettner, G. R. and Oberley, L. W. (1978) Biochem. Biophys. Res. Commun. 83 69-74

22 Buettner, G. R. (1990) Free Radicals Res. Commun. 10, 11-15

23 Mason, R. P. (1984) Methods Enzymol. 105, 416-422

24 Duling, D. R. (1994) J. Magn. Res. Ser. B 104, 105-110

25 Chamulitrat, W., Takahashi, N. and Mason, R. P. (1989) J. Biol. Chem. 264, 7889-7899

26 Rosen, G. M. and Rauckman, E. J. (1980) Mol. Pharmacol. 17, 233-238

27 Gunther, M. R., Kelman, D. J., Corbett, J. T. and Mason, R. P. (1995) J. Biol. Chem. 270, 16075-16081

28 Rustgi, S., Joshi, A., Moss, H. and Riesz, P. (1977) Int. J. Radiat. Biol. 31, 415-440

29 Blumberg, W. E. (1981) Methods Enzymol. 76, 312-329

30 Russell, G. A. (1957) J. Am. Chem. Soc. 79, 3871-3877
31 Ingold, K. U. (1969) Acc. Chem. Res. 2, 1-9

32 Allentoff, A. J., Bolton, J. L., Wilks, A., Thompson, J. A. and Ortiz de Montellano, P. R. (1992) J. Am. Chem. Soc. 114, 9744-9749

33 Tappel, A. L. (1961) in Autoxidation and Antioxidants, vol. 1, (Lundberg, W. 0., ed.), pp. 325-366, John Wiley, New York

34 Davies, M. J., Gilbert, B. C. and Haywood, R. M. (1991) Free Radicals Res. Commun. 15, 111-127

35 Davies, M. J., Fu, S. L. and Dean, R. T. (1995) Biochem. J. 305, 643-649

36 Mansuy, D., Bartoli, J.-F. and Momenteau, M. (1982) Tetrahedron Lett. 23 $2781-2784$

37 Meunier, B. (1992) Chem. Rev. 92, 1411-1456

38 Dickerson, R. E. and Geis, I. (1983) in Haemoglobin (Dickerson, R. E. and Geis, I., eds.), pp. 26-60, Benjamin/Cummings, Menlo Park,. CA

Received 22 July 1996/28 October 1996; accepted 7 November 1996 